\title{
HUBUNGAN POLA KONSUMSI IKAN TERHADAP KADAR KOLESTEROL PADA LANSIA DI POSYANDU AISYIYAH CABANG SOLO UTARA RANTING BANYUANYAR
}

\author{
Aurulia Banuar Anggarianti ${ }^{1}$, Setyaningrum Rahmawaty ${ }^{2}$, Elida Soviana ${ }^{3}$ \\ ${ }^{1}$ RSI Jemursari Surabaya. J1. Jemursari 51-57 Surabaya \\ Email : 1 auruliab@gmail.com \\ ${ }^{2,3}$ Program Studi Ilmu Gizi FIK UMS. Jl. A. Yani Tromol Pos I Pabelan Surakarta. \\ Email: ${ }^{2}$ Setyaningrum.Rahmawaty@ums.ac.id ,3.elida.soviana@ums.ac.id
}

\begin{abstract}
ABSTRAK
Ikan merupakan salah satu bahan makanan yang memiliki manfaat sangat berguna, diantaranya dapat menurunkan kadar kolesterol, menurunkan tekanan darah serta memperkecil risiko serangan jantung pada lansia. Mengetahui hubungan pola konsumsi ikan (jenis, jumlah dan frekuensi) terhadap kadar kolesterol pada lansia di Posyandu Aisyiyah Cabang Solo Utara. Penelitian ini menggunakan metode cross sectional dengan melibatkan 42 lansia yang berusia 46-75 tahun, pengambilan sampel menggunakan teknik consecutive sampling. Penelitian ini dilakukan di Posyandu Lansia Aisyiyah Cabang Solo Utara Ranting Banyuanyar. Data pola konsumsi ikan yang terdiri dari jenis, jumlah dan frekuensi konsumsi ikan didapatkan dengan menggunakan semi quantitative food frequency questionnaire dan kadar kolesterol darah lansia didapatkan dengan cara mengambil sampel darah kapiler menggunakan metode electrode-based biosensor. Duapuluh dua (64,7\%) responden mengkonsumsi non oily fish, 23 (67,6\%) responden memiliki jumlah konsumsi ikan kurang, 29 $(85,3 \%)$ responden memiliki frekuensi konsumsi ikan baik dan 19 $(55,9 \%)$ responden memiliki kadar kolesterol tinggi. Hasil uji korelasi menunjukkan tidak terdapat hubungan jenis konsumsi ikan dengan kadar kolesterol yang memiliki nilai $p=1,00$; jumlah konsumsi ikan terhadap kadar kolesterol memiliki nilai $p=0,060$ sedangkan untuk frekuensi konsumsi ikan memiliki nilai $p=0,201$. Konsumsi oily fish dapat menurunkan kadar kolesterol darah walaupun secara statistik tidak terdapat hubungan antara pola konsumsi ikan terhadap kadar kolesterol.
\end{abstract}

Kata kunci : Pola konsumsi ikan, oily fish, non oily fish, kadar kolesterol

\footnotetext{
ABSTRACT

Fish is high in omega-3 fatty acids, research has shown that omega-3 fatty acids in fish degrade cholesterol plasma, degrade blood pressure and prevent coronary heart disease in elderly. The present study aimed to assess the relationship between the consumption of fish including type, number, and frequency with cholesterol levels in elderly at Posyandu Aisyiyah Cabang Solo Utara Ranting Banyuanyar. A cross
} 
sectional study was conducted in a consecutive sampling of 42 elderly aged 46-75 years in Posyandu Aisyiyah Cabang Solo Utara Ranting Banyuanyar. An average of semi quantitative food frequency questionnaire to obtain consumption of fish . Plasma cholesterol was taken using electrode-based biosensor method. Twenty two $(64,7 \%)$ participants was consumption non oily fish, $23(67,6 \%)$ participants had low average of fish consumption $(<14,29 \mathrm{gr} /$ day $), 29(85,3 \%)$ participants had high frequency of fish consumption ( $\geq 4$ twice/month) and $19(55,9 \%)$ participants had high plasma cholesterol. There is no relationship between fish type with plasma cholesterol $(p=1,00)$, no relationship between number of fish consumption with plasma cholesterol $(p=0,060)$ as well as frequency fish consumption with plasma cholesterol $(\mathrm{p}=0,201)$. Oily fish consumption may increase plasma cholesterol although statistical test not showing significant correlation between fish consumption with plasma cholesterol.

Keywords : Fish Consumption, oily fish, non oily fish, total cholesterol level

\section{PENDAHULUAN}

Lanjut usia (lansia) memiliki berbagai perubahan fungsi organ, salah satunya yaitu terjadi penurunan elastisitas pada pembuluh darah, yang diakibatkan oleh pengendapan bahan-bahan yang bersifat ateroskerotik diantaranya adalah kolesterol (Almatsier, 2011).

Hiperkolesterolemia pada masyarakat perkotaan perlu mendapatkan perhatian khusus, sebab prevalensi hiperkolesterolemia yang terjadi pada wilayah perkotaan sebesar 39,5\%. Angka tersebut tergolong tinggi dibandingkan dengan prevalensi hiperkolesterolemia pada wilayah pedesaan sebesar $32,1 \%$ (Riskesdas, 2013).

Ikan merupakan salah satu bahan makanan yang memiliki manfaat yang sangat berguna. Manfaat yang dimiliki dengan mengkonsumsi ikan diantaranya menurunkan kadar kolesterol dan tekanan darah serta memperkecil risiko serangan jantung. Ikan memiliki kandungan lemak yaitu asam lemak omega-3 dan omega-6 yang tinggi (Kaplan, 1994).

Asam lemak omega-3 dapat menurunkan kadar kolesterol dengan cara meningkatkan konsentrasi High Density Lipoprotein (HDL) dan meningkatkan diameter partikel HDL. Konsentrasi HDL yang meningkat di dalam darah akan mempermudah kolesterol untuk dapat diedarkan kembali ke hati untuk di metabolisme kembali. Asam lemak omega-3 mengurangi proinflamasi sitokin yang berperan sebagai mediator dan pengatur imunitas, inflamasi dan hematopoesis dari sel yang terlibat dalam terjadinya aterosklerosis (Bowman et al, 2006).

Survei pendahuluan yang dilakukan pada bulan Mei 2015 di Dinas Kesehatan Kota Surakarta didapatkan data cakupan pelayanan kesehatan pada lansia di wilayah Solo Utara tahun 2012 sebesar $51,975 \%$, tahun 2013 sebesar 67,48\% dan tahun 2014 sebesar 60,295\% sedangkan di wilayah Solo Selatan pada tahun 2012 sebesar 55,6\%, tahun 2013 sebesar 81,45\% dan tahun 2014 sebesar 61,373\%. Angka ini menggambarkan cakupan pelayanan kesehatan lansia di Solo Utara selama 3 tahun terakhir lebih rendah dibandingkan dengan Solo Selatan.

Survei pendahuluan dilakukan di Puskemas Banjarsari dan Puskesmas 
Gambirsari, puskesmas ini merupakan puskesmas yang berada di wilayah Aisyiyah cabang Solo Utara. Berdasarkan hasil survei pendahuluan tersebut didapatkan data jumlah lansia yang mengalami hiperkolesterolemia dalam sebulan memiliki rata-rata sebesar $77,27 \%$. Sedangkan data jumlah non lansia yang mengalami hiperkolesterolemia dalam sebulan memiliki rata-rata sebesar $22,72 \%$. Angka tersebut menggambarkan bahwa lansia yang mengalami hiperkolesterolemia lebih tinggi dibandingkan dengan usia yang belum lansia. Tingkat konsumsi ikan masyarakat kota Solo adalah 3,8 kg ikan selama setahun, hal ini tergolong rendah dibandingkan dengan target tingkat konsumsi ikan Indonesia sebesar 31,64 kg per orang dalam setahun.

Kadar kolesterol darah dipengaruhi oleh 2 faktor yaitu faktor endogen yang terdiri dari usia, jenis kelamin, faktor genetik dan faktor eksogen yang terdiri dari obesitas, aktifitas fisik, asupan lemak jenuh, asupan kolesterol, diabetes dan obat (Guyton, 2007).

Berdasarkan hal tersebut, maka peneliti ingin mengetahui hubungan pola konsumsi ikan terhadap kadar kolesterol pada lansia di Posyandu Aisyiyah Cabang Solo Utara.

\section{METODE PENELITIAN}

Jenis penelitian ini adalah penelitian observational dengan pendekatan cross sectional, pengambilan data dilakukan pada bulan Agustus 2015, di posyandu lansia Aisyiyah Cabang Solo Utara.

\section{Responden}

Sebanyak 42 lansia terlibat dalam penelitian ini yang diambil dengan teknik consecutive sampling, dimana semua subjek yang memenuhi kriteria pemilihan dimasukkan dalam penelitian sampai jumlah subjek yang diperlukan terpenuhi. Total responden terdiri dari 34 responden yang mengkonsumsi ikan dan 8 responden yang tidak mengkonsumsi ikan.

\section{Pola Konsumsi Ikan}

Pengumpulan data pola konsumsi ikan dalam penelitian ini didapatkan dengan cara wawancara langsung dengan responden menggunakan semi quantitative food frequency questionnaire selama satu tahun terakhir yang terdiri dari jumlah ikan yang dikonsumsi, frekuensi makan ikan dan jenis ikan yang dikonsumsi.

\section{Kadar Kolesterol}

Kadar Kolesterol didapatkan dengan cara mengambil sampel darah kapiler pasien 1-2 hari setelah dilakukan wawancara. Menggunakan alat easy touch dengan metode electrode-based biosensor.

\section{Analisis Data}

Analisis data disajikan dalam tabel distribusi dan variabel yang diteliti meliputi pola konsumsi ikan yang terdiri dari jenis ikan yang dikonsumsi, jumlah konsumsi ikan dan frekuensi konsumsi ikan, variabel kadar kolesterol darah pada lansia. Untuk mendeskripsikan data yang diperoleh berupa data distribusi dan presentase. Uji statistik yang digunakan dalam penelitian ini adalah Fisher's Exact dan Rank Spearman's.

\section{HASIL DAN PEMBAHASAN}

\section{Karakteristik Sampel Penelitian}

Sampel yang digunakan dalam penelitian ini adalah lansia yang berada di Posyandu Lansia Aisyiyah cabang Solo Utara Ranting Banyuanyar yang sesuai dengan kriteria inklusi dan eksklusi yang telah ditentukan oleh peneliti. Sesuai dengan hasil penelitian diperoleh data responden penelitian meliputi distribusi berdasarkan usia, jenis kelamin, pendidikan, pekerjaan, pendapatan, dan pengetahuan gizi dapat dilihat pada Tabel 1. 
Tabel 1.

Karakteristik Responden ( $\mathrm{n}=34)$

\begin{tabular}{lcc}
\hline Karakteristik & $\mathrm{N}$ & $\begin{array}{c}\text { Persentase } \\
(\%)\end{array}$ \\
\hline Usia & & \\
Lansia Awal & 10 & 29,41 \\
Lansia Akhir & 12 & 35,29 \\
Manula & 12 & 35,29 \\
\hline Jenis Kelamin & & \\
Laki - laki & 11 & 32,4 \\
$\quad$ Perempuan & 23 & 67,6 \\
\hline Tingkat Pendidikan & & \\
Tidak sekolah & 8 & 23,5 \\
Sekolah dasar & 13 & 38,2 \\
SMP & 4 & 11,8 \\
SMA & 8 & 23,5 \\
Perguruan tinggi & 1 & 2,9 \\
\hline Pekerjaan & & \\
Tidak bekerja & 13 & 38,2 \\
Swasta & 15 & 44,11 \\
PNS/pensiunan & 2 & 5,9 \\
Lain - lain & 4 & 11,76 \\
\hline Pendapatan & & \\
Kurang dari UMR & 20 & 58,8 \\
UMR & 14 & 41,2 \\
\hline Pengetahuan Gizi & & \\
Kurang & 5 & 14,7 \\
Baik & 29 & 85,3 \\
\hline
\end{tabular}

Berdasarkan Tabel 1 kategori umur pada penelitian ini dibedakan menjadi 3 yaitu lansia awal (46 - 55 tahun), lansia akhir (56 - 65 tahun) dan manula (>65 tahun). Pada penelitian ini sebagian besar responden penelitian berada pada kelompok lansia akhir (56 - 65 tahun) dan manula sebanyak 12 orang $(35,29 \%)$ dan responden pada penelitian ini yang berjenis kelamin perempuan sebanyak 23 orang $(67,6 \%)$ dan yang berjenis kelamin laki-laki sebanyak 11 orang $(32,4 \%)$.

Pada penelitian ini responden sebagian besar memiliki tingkat pendidikan sekolah dasar sebanyak 13 orang $(38,2 \%)$. Responden pada penelitian ini sebagian besar memiliki pekerjaan swasta sebanyak 15 orang $(44,11 \%)$ dan tidak bekerja sebanyak 13 orang $(38,2 \%)$.

Pada penelitian ini sebagian besar responden memiliki pendapatan kurang dari UMR sebanyak 20 orang $(58,8 \%)$ dan pendapatan sesuai UMR sebanyak 14 orang (41,2\%). Responden pada penelitian ini sebagian besar memiliki pengetahuan gizi yang baik sebesar $85,3 \%$ dan responden yang memiliki pengetahuan gizi rendah sebesar $14,7 \%$.

Tabel 2. Pola Konsumsi Ikan $(n=34)$

\begin{tabular}{lcc}
\hline \multicolumn{1}{c}{ Variabel } & $\mathrm{N}$ & $\begin{array}{c}\text { Persentase } \\
(\%)\end{array}$ \\
\hline Jenis ikan & & \\
$\quad$ Non oily fish & 22 & 64,7 \\
$\quad$ Oily fish & 12 & 35,3 \\
\hline Jumlah konsumsi ikan & & \\
$\quad$ Baik & 11 & 32,4 \\
$\quad$ Kurang & 23 & 67,6 \\
\hline Frekuensi konsumsi ikan & & \\
Baik & 29 & 85,3 \\
$\quad$ Kurang & 5 & 14,7 \\
\hline Kadar kolesterol & & \\
$\quad$ Normal (<200 mg/dL) & 0 & 0 \\
Batas tinggi (200-239 & 15 & 44,1 \\
mg/dL) & & \\
Tinggi $(\geq 240 \mathrm{mg} / \mathrm{dL})$ & 19 & 55,9 \\
\hline
\end{tabular}

Berdasarkan Tabel 2, dari 34 responden yang mengkonsumsi ikan diketahui bahwa lansia yang mengkonsumsi non oily fish lebih tinggi dengan persentase sebesar $64,7 \%$ dan mengkonsumsi oily fish sebesar 35,3\%. Berdasarkan jumlah konsumsi ikan 11 responden $(32,4 \%)$ termasuk dalam kategori jumlah konsumsi ikan baik, dan 23 responden $(67,6 \%)$ memiliki jumlah konsumsi ikan kurang. Berdasarkan WHO (2003) jumlah konsumsi ikan sebanyak 14,29 gram/hari dapat mencegah terjadinya penyakit kardiovaskuler pada seseorang.

Berdasarkan frekuensi konsumsi ikan 29 responden (85,3\%) termasuk dalam kategori frekuensi konsumsi ikan baik dan 5 responden $(14,7 \%)$ memiliki frekuensi konsumsi ikan kurang. Berdasarkan WHO (2003) frekuensi konsumsi ikan 4 kali/bulan dapat mencegah terjadinya penyakit kardiovaskuler pada seseorang.

Berdasarkan kadar kolesterol sebagian besar responden memiliki kadar kolesterol tinggi sebanyak 19 orang 
(55,9\%). Rata-rata kadar kolesterol pada lansia di Posyandu Aisyiyah Cabang Solo Utara sebesar 253,06 mg/dL.

Tabel 3. Gambaran Kadar Kolesterol berdasarkan Jenis Konsumsi Ikan

\begin{tabular}{lcc}
\hline & $\begin{array}{c}\text { Oily } \\
\text { fish }\end{array}$ & Non oily fish \\
\hline Total Sampel & 12 & 30 \\
Mean & 244,75 & 250,70 \\
Minimum & 204 & 185 \\
Maximum & 336 & 360 \\
\hline
\end{tabular}

Berdasarkan Tabel 3 menunjukkan bahwa rata-rata kadar kolesterol pada lansia yang mengkonsumsi ikan oily fish lebih rendah $(244,75 \mathrm{mg} / \mathrm{dL})$ dibandingkan dengan lansia yang mengkonsumsi non oily fish $\quad(250,70$ $\mathrm{mg} / \mathrm{dL}$ ). Berdasarkan data tersebut didapatkan hasil bahwa lansia yang mengkonsumsi oily fish memiliki nilai maksimum (336 $\mathrm{mg} / \mathrm{dL})$ yang lebih rendah dibandingkan dengan lansia yang mengkonsumsi non oily fish $(360 \mathrm{mg} / \mathrm{dL})$.

\section{Analisis Bivariat}

Hubungan Antara Jenis, Jumlah dan Frekuensi Konsumsi Ikan dengan Kadar Kolesterol pada Lansia

Data pola konsumsi ikan yang terdiri dari jenis ikan, jumlah konsumsi ikan dan frekuensi konsumsi ikan sampel didapatkan dengan menggunakan semy quantitative food frequency quesionaire selama satu tahun terakhir. Data diambil sebelum dilakukannya pengecekan kadar kolesterol.

Tabel 4. Distribusi Kadar Kolesterol Berdasarkan Jenis Konsumsi Ikan

\begin{tabular}{|c|c|c|c|c|c|c|c|}
\hline \multirow{3}{*}{$\begin{array}{l}\text { Jenis } \\
\text { ikan }\end{array}$} & \multicolumn{4}{|c|}{ Kadar Kolesterol Lansia } & \multirow{2}{*}{\multicolumn{2}{|c|}{ Total }} & \multirow{3}{*}{$\begin{array}{c}p^{*} \\
\text { value }\end{array}$} \\
\hline & \multicolumn{2}{|c|}{ Normal } & \multicolumn{2}{|c|}{ Tinggi } & & & \\
\hline & $\mathrm{N}$ & $\%$ & $\mathrm{~N}$ & $\%$ & $\mathrm{~N}$ & $\%$ & \\
\hline $\begin{array}{l}\text { Non } \\
\text { oily }\end{array}$ & 0 & 0 & 22 & 100 & 22 & 100 & \\
\hline $\begin{array}{l}\text { fish } \\
\text { Oily } \\
\text { fish }\end{array}$ & 0 & 0 & 12 & 100 & 12 & 100 & 1,00 \\
\hline Total & 1 & & 41 & & 42 & & \\
\hline
\end{tabular}

Hubungan Pola Konsumsi Ikan... (Aurulia Banuar Anggarianti, Setyaningrum Rahmawaty, Elida Soviana)
Berdasarkan Tabel 4, hasil penelitian menunjukkan bahwa dari 22 responden mengkonsumsi non oily fish dan terdapat $100 \%$ memiliki kadar kolesterol yang tinggi dan dari 12 responden yang mengkonsumsi oily fish terdapat $100 \%$ memiliki kadar kolesterol tinggi. Hasil uji analisis Fisher's Exact didapatkan nilai $p=1.00(p>0,05)$ maka Ho ditolak, sehingga dapat disimpulkan bahwa tidak ada hubungan antara jenis konsumsi ikan terhadap kadar kolesterol pada lansia di posyandu Aisyiyah Cabang Solo Utara. Analisis jumlah konsumsi ikan dengan kadar kolesterol pada lansia dapat dilihat pada Tabel 5 sebagai berikut.

Tabel 5

Distribusi Kadar Kolesterol Berdasarkan Frekuensi Konsumsi Ikan Oily Fish

\begin{tabular}{lcccc}
\hline $\begin{array}{l}\text { Variabel } \\
\text { Penelitian }\end{array}$ & Mean & Median & IQR & $\begin{array}{c}p^{*} \\
\text { value }\end{array}$ \\
\hline $\begin{array}{l}\text { Jumlah } \\
\text { konsumsi }\end{array}$ & $\begin{array}{c}12,71 \\
\text { gr/hari }\end{array}$ & $\begin{array}{c}8,23 \\
\text { gr/hari }\end{array}$ & $\begin{array}{c}11,46 \\
\text { gr/hari }\end{array}$ & 0,060 \\
ikan & & & & \\
Frekuensi & 14,73 & 10,00 & 21,00 & 0,201 \\
konsumsi & kali/ & kali/ & kali/ & \\
ikan & bulan & bulan & bulan & \\
Kadar & 253,06 & 247 & 47 & \\
kolesterol & mg/dL & mg/dL & mg/dL & \\
\hline
\end{tabular}

Berdasarkan Tabel 5 didapatkan rata-rata jumlah konsumsi ikan sebesar 12,71 gr/hari dengan nilai median 8,23 gr/hari dan nilai Inter-quartile range (IQR) yang merupakan nilai penyebaran data jumlah konsumsi ikan sebesar 11,46 gr/hari. Hasil uji analisis Rank Spearman didapatkan nilai $p=0,060(p>0,05)$ maka Ho ditolak. Sedangkan hasil uji korelasi antara jumlah konsumsi ikan terhadap kadar kolesterol pada lansia di Posyandu Aisyiyah Cabang Solo Utara.

Berdasarkan Tabel 5 didapatkan rata-rata frekuensi konsumsi ikan 14,73 kali/bulan dengan nilai median 10,00 kali/bulan dan nilai Inter-quartile range (IQR) yang merupakan nilai sebaran data frekuensi konsumsi ikan sebesar 21 kali/bulan. Hasil penelitian menunjukan 
bahwa rata-rata kadar kolesterol lansia sebesar 253,06 mg/dL dan diketahui nilai Inter-quartile range (IQR) yang merupakan nilai penyebaran data kadar kolesterol sebesar $47 \mathrm{mg} / \mathrm{dL}$. Hasil uji analisis Rank Spearman dan didapatkan nilai $p=0,201(p>0,05)$ maka Ho ditolak, sehingga tidak terdapat hubungan antara frekuensi konsumsi ikan terhadap kadar kolesterol pada lansia di Posyandu Aisyiyah Cabang Solo Utara.

Menurut National Heart Foundation of Australia (2008) Oily fish adalah ikan yang memiliki kandungan lemak kurang dari $10 \%$ dan lebih banyak mengandung omega-3. Kandungan omega-3 pada ikan oily fish dapat menurunkan kadar kolesterol dalam darah dengan cara meningkatkan konsentrasi HDL dan meningkatkan partikel HDL (Bowman et al, 2006). Berdasarkan teori yang disampaikan Heslet (2007) usia lanjut memiliki kadar kolesterol lebih tinggi, hal ini disebabkan karena semakin bertambah umur seseorang maka aktifitas reseptor LDL makin berkurang sehingga pengaturan peredaran kolesterol dalam darah juga menurun.

Faktor pola konsumsi ikan yang sangat berpengaruh terhadap pola konsumsi lansia di Posyandu Aisyiyah Cabang Solo Utara adalah faktor aksesibilitas. Masyarakat cenderung mengkonsumsi bahan makanan yang lebih dekat untuk didapatkan, masyarakat lansia lebih memilih bahan makanan yang tersedia di penjual keliling dibandingkan berbelanja di supermarket yang memiliki macam dan jenis bahan makanan yang lebih lengkap. Berdasarkan teori yang disampakan Suryana (2004) bahwa ketersediaan dan distribusi bahan pangan merupakan salah satu faktor yang sangat berpengaruh terhadap pola konsumsi masyarakat.

\section{KESIMPULAN}

1. Tidak terdapat hubungan antara jenis konsumsi ikan dengan kadar kolesterol pada lansia di posyandu Aisyiyah cabang Solo Utara.

2. Tidak terdapat hubungan jumlah konsumsi ikan dengan kadar kolesterol pada lansia di posyandu Aisyiyah cabang Solo Utara.

3. Tidak terdapat hubungan frekuensi konsumsi ikan dengan kadar kolesterol pada lansia di posyandu Aisyiyah cabang Solo Utara.

\section{DAFTAR PUSTAKA}

Almatsier, S., Soetardjo, S., Soekatri, M., 2011, Gizi Seimbang dalam Daur Kehidupan. Gramedia Pustaka Utama, Jakarta.

Bowman, B.A dan R.M. Russell., 2006, Present Knowledge in Nutrition, ILSI Press, Washington DC.

Guyton, A.C dan Hall, J.E., 2007, Textbook of Medical Physiology, Elsevier Saunders, Philadelphia, PA USA.

Heslet, L., 2007, Kolesterol yang Perlu Anda Ketahui, Kesaint Blanc, Jakarta.

Kaplan., 1994, Pencegahan Penyakit Jantung Koroner, Buku Kedokteran EGC, Jakarta. 
National Heart Foundation of Australia, 2008, Omega-3 : General, National Heart Foundation of Australia, Australia.

Riset Kesehatan Dasar., 2013, Badan Penelitian dan Pengembangan Kesehatan, Departemen Kesehatan Republik Indonesia, Jakarta.

Suryana, A., 2004, Ketahanan Pangan di Indonesia, Makalah pada Widyakarya nasional Pangan dan Gizi VIII, LIPI, Jakarta.

WHO, 2003, Diet, Nutrition and The Prevention of Chronic Diseases, Geneva: World Health Organization. 
JURNAL KESEHATAN, ISSN 1979-7621, Vol. 1, No. 2, Desember 2016 
JURNAL KESEHATAN, ISSN 1979-7621, Vol. 1, No. 2, Desember 2016 